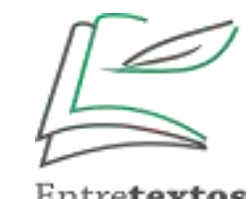

Entretextos 21(3): especial, 2021

ISSN (digital): 2764-0809

ISSN (impresso): 1519-5392

DOI: $10.5433 / 1519-5392.2021 v 21 n 3 E s p . p 163$

\title{
Propostas de ensino de conhecimentos linguístico- discursivos em português (segunda língua) e desenvolvimento da atividade metalinguística
}

\section{Proposals for teaching linguistic-discursive knowledge in Portuguese (second language) and development of metalinguistic activity}

\section{Propuestas para la enseñanza de conocimientos lingüístico- discursivos en portugués (segunda lengua) y desarrollo de la actividad metalingüística}

\author{
Damián Díaz ${ }^{1}$ \\ https://orcid.org/0000-0002-0825-5302 \\ Gladys Quevedo-Camargo² \\ (iD) https://orcid.org/0000-0002-0825-5302
}

\begin{abstract}
RESUMO: Esse artigo analisa os resultados da aplicação de atividades epilinguísticas e metalinguísticas (GERALDI, 1991; 1996) em uma Sequência Didática sobre o gênero artigo de opinião no marco de um curso de preparação do Exame Celpe-Bras, tendo como foco a atividade metalinguística grupal e individual desenvolvida pelos alunos. $O$ embasamento teórico é a concepção de linguagem como atividade social organizada em gêneros do Interacionismo Sociodiscursivo e uma definição sócio cultural e interindividual da atividade metalinguística. Os dados foram analisados em forma qualitativa (conceitos e termos metalinguísticos) e derivam do registro de interações em sala de aula em torno das atividades mencionadas, assim como de entrevistas retrospectivas à escrita realizadas no início e no final da sequência didática. As análises permitem afirmar que a realização das atividades estimulou a construção grupal de conhecimento sobre o gênero e de metalinguagem, assim como a mobilização individual desses meios na escrita.
\end{abstract}

PALAVRAS-ChAVE: Ensino de PL2. Conhecimento linguístico-discursivo. Atividade metalinguística.

ABSTRACT: This article analyzes the results of the application of epilinguistic and metalinguistic activities (GERALDI, 1991; 1996) in a Didactic Sequence about the genre opinion article within the framework of a preparation course for the Celpe-Bras Exam focusing on group and individual

\footnotetext{
1 Mestre em Linguística Aplicada. Facultad de Información y Comunicación (FIC), Universidad de la República (UdelaR). E-mail: damian.diaz@fic.edu.uy.

2 Doutora em Estudos da Linguagem. Instituto de Letras (IL), Universidade de Brasília (UnB). E-mail: gladys@unb.br.
} 
metalinguistic activity developed by the students. The theoretical basis is the conception of language as a social activity organized in genres from Sociodiscursive Interactionism and a sociocultural and inter-individual definition of metalinguistic activity. The data were analyzed in a qualitative way (metalinguistic concepts and terms) and are derived from the record of interactions in the classroom around the mentioned activities, as well as retrospective written interviews carried out at the beginning and at the end of the didactic sequence. The analyzes allow us to state that carrying out the activities stimulated the group construction of knowledge about gender and metalanguage, as well as the individual mobilization of these means in writing.

KEYWORDS: PL2 teaching. Linguistic-discursive knowledge. Metalinguistic activity.

RESUMEN: Este artículo analiza los resultados de la aplicación de actividades epilingüísticas y metalingüísticas (GERALDI, 1991; 1996) en una Secuencia Didáctica sobre el género artículo de opinión en el marco de un curso de preparación del Examen Celpe-Bras centrando el análisis en la actividad metalingüística grupal e individual desarrollada por los estudiantes. Nuestro marco teórico es la concepción de lenguaje como actividad social organizada en géneros del Interaccionismo Sociodiscursivo y una definición sociocultural e interindividual de la actividad metalingüística. Los datos fueron analizados de forma cualitativa (conceptos y términos metalingüísticos) y se derivan del registro de interacciones en el aula en torno a las actividades mencionadas, así como de entrevistas retrospectivas a la escritura realizadas al inicio y al final de la secuencia didáctica. Los análisis permiten afirmar que la realización de las actividades estimuló la construcción grupal de conocimientos sobre el género y de metalenguaje, así como la movilización individual de estos medios en la escritura.

PALABRAS ClaVe: Enseñanza de PL2. Conocimiento lingüístico-discursivo. Actividad metalingüística.

\section{Introdução}

O lugar dado ao ensino explícito da "gramática" ou dos conhecimentos sobre a linguagem nas aulas de segundas línguas e línguas estrangeiras tem sido motivo de controvérsia na história da didática (KLETT, 2004). Assim, o ensino explícito do conhecimento linguístico foi central na abordagem da gramática e da tradução, tornouse subsidiário no audiolingualismo e no cognitivismo, foi rejeitado pela abordagem da compreensão, até ser rediscutido e conceituado de diferentes maneiras pelos promotores da abordagem comunicativa (CELCE-MURCIA, 1991).

Nos últimos 30 anos, modelos específicos para o ensino do conhecimento linguístico têm sido desenvolvidos. Entre os mais relevantes, destaca-se o de Schmidt (1990), que, a partir de sua denominada "hipótese da percepção" (noticing hypothesis), propõe a realização de tarefas destinadas ao tratamento de aspectos específicos do funcionamento da língua-alvo. Nelas, os conhecimentos devem ser reconhecidos pelos alunos, explicados pelo professor e revisados em seu uso prático. O método identificado como "abordagem PPP" (PPP approach: presentation, practice and production) também defende a instrução explícita e propõe três fases de trabalho com aspectos discretos da 
língua: sua apresentação explícita, a prática de seu funcionamento e o uso em produções específicas (NORRIS; ORTEGA, 2000).

Por sua vez, Celce-Murcia (1991) apresenta uma abordagem metodológica em que só são ensinados os aspectos gramaticais necessários para os contextos sociais de uso em que se espera que os alunos atuem, tendo que se ensinar os aspectos formais, semânticos e discursivos, bem como o papel que desempenham em determinados gêneros e registros. Os estudos liderados por Donato (1994), baseados na teoria sociocultural de Vygotsky, propõem duas condições essenciais para o ensino do conhecimento sobre a língua em L2: a realização de atividades de discussão grupal e a promoção de momentos de colaboração entre pares; essas condições visam potencializar o apoio coletivo dos processos de construção de conhecimento (peer scaffolding). Finalmente, Larsen-Freeman (2014) propõe o conceito de grammaring, que consiste em um método progressivo de ensino de conhecimentos sobre a linguagem (morfossintáticos, semânticos e pragmáticos), que conduz os alunos a aplicar esses saberes à produção de textos em contextos plausíveis de comunicação e de forma recursiva, a fim de favorecer sua apropriação.

No contexto específico do ensino de português como segunda língua (L2) e língua estrangeira (LE), o papel dado ao ensino dos conhecimentos sobre a língua ou gramática também tem recebido atenção em pesquisas nos últimos 20 anos. Diversos trabalhos têm analisado materiais didáticos editados e constatado suas carências de contextualização e completude (BRANDÃO, 2010; BROCCO, 2009; MARCOTULIO, PINHEIRO, ASSIS, 2015; MELO, 2017; MITELSTADT, SANTOS, 2012; RODRIGUES, 2015; SILVEIRA, ROSSI, 2006; TAFNER, 2005, entre outros). Outros têm apresentado propostas para o ensino de determinados conhecimentos gramaticais, algumas validadas por sua aplicação prática (KRUG, 2009; LIMA, 2012; MAURÍCIO, 2015; SILVA, 2019), outras publicadas como sugestões metodológicas (MEDEIROS, 2001; NADAIS, 2009; PABST, 2014; PRATAS, 2017), embora nenhum desses trabalhos apresente uma metodologia geral.

A discussão sobre o papel dado ao ensino de conhecimentos sobre a linguagem se insere no nosso trabalho dentro do Interacionismo Sociodiscursivo (ISD). Vários trabalhos do ISD discutem de que forma esses conhecimentos devem ser ensinados. Embora existam diferenças pontuais, todos defendem que a reflexão indutiva 
verbalizada, individual ou coletiva, é a principal estratégia para ensinar os conhecimentos linguístico-discursivos. Em outras palavras, os alunos devem aprofundar sua compreensão autônoma do funcionamento da linguagem a partir da troca entre pares e com o auxílio da metalinguagem (CAMPS, 2009; DOLZ; ERARD, 2000; DOLZ; SCHNEUWLY, 2004; PONTARA; CRISTOVÃO, 2017).

Uma dessas pesquisas, realizada no contexto brasileiro por Pontara e Cristovão (2017) e em relação ao ensino de inglês língua estrangeira ${ }^{3}$, retomou as propostas de Geraldi (1991; 1996) para o ensino de conhecimentos sobre a linguagem por meio de práticas de análise linguística em atividades denominadas "epilinguísticas" e "metalinguísticas". De acordo com as autoras (PONTARA; CRISTOVÃO, 2017), essas atividades, inseridas no contexto de sequências didáticas (SDs), possibilitam um ensino dos conhecimentos que integra seu uso ao desenvolvimento da capacidade de produzir textos.

Neste artigo, analisamos a aplicação do mesmo tipo de atividades em uma SD para o ensino de português como L2 e tendo como objetivo a aprendizagem do artigo de opinião. O nosso intuito é analisar a atividade metalinguística grupal suscitada por essas atividades, assim como a atividade metalinguística individual dos alunos ao escrever. Consideramos que essas análises nos permitem avaliar a contribuição das atividades epilinguísticas e metalinguísticas à aprendizagem e, particularmente, ao desenvolvimento da capacidade de autorregular a escrita ${ }^{4}$. Os dados foram coletados mediante gravação e transcrição das interações grupais suscitadas por atividades epilinguísticas e metalinguísticas e gravação e transcrição de duas entrevistas retrospectivas à escrita realizadas com duas alunas, no início e no final da SD. As análises foram qualitativas e tiveram como foco os conceitos mobilizados nas interações assim como os termos metalinguísticos utilizados. A fim de tornar o objetivo exequível, abordamos unicamente atividades em que foi trabalhada a modalização, assim como os segmentos das entrevistas relativos à regulação desse aspecto textual.

\section{Fundamentação teórica}

Para o Interacionismo Sociodiscursivo (ISD), os textos orais e escritos são

\footnotetext{
${ }^{3}$ Ferraz e Pinheiro (2014) aplicaram o mesmo tipo de atividades para o ensino da escrita em PL2. Esse trabalho, embora não enquadrado dentro do ISD, é antecedente do nosso.

${ }^{4}$ Para acessar um relatório mais aprofundado da pesquisa, sugerimos a leitura de Díaz (2019).
} 
produzidos no marco de atividades que condicionam os comportamentos individuais (BRONCKART, 1999). Dessa forma, cada texto empírico evidencia a apropriação, por um agente, das propriedades de uma atividade social e de linguagem (BRONCKART, 1999). Esse conhecimento social se condensa em gêneros de textos, que são formas de ação estabilizadas que sintetizam as relações entre as atividades sociais e a linguagem (NASCIMENTO, 2019).

Segundo essa concepção, o agente, ao produzir um texto, toma decisões a respeito dos diferentes níveis de sua organização, reguladas por suas representações do contexto (MACHADO, 2005). Supõe-se que essa tomada de decisões requer processos conscientes, especialmente no caso de textos dos gêneros secundários (BAKHTIN, 2008; SCHNEUWLY, 2004). Para Bronckart (1999, 2009), esse caráter consciente é sustentado pela mediação dos signos linguísticos, que possibilitam a manipulação (evocação, modificação, ampliação, relação) de unidades discretas na mente (representações). Segundo Vygotsky (1987), é possível diferenciar dois tipos de representação de acordo com seu nível de generalização. Por um lado, os conceitos espontâneos são construídos a partir da experiência cotidiana e se vinculam diretamente a raciocínios ou objetos particulares. Por outro, os conceitos científicos são apreendidos no contexto escolar e têm um caráter generalizado que não os vincula a raciocínios ou objetos particulares, pois trata-se de representações referidas aos próprios processos mentais.

A diferenciação em níveis de consciência proposta por Vygotsky vai ao encontro das propostas de Culioli e Normand (2005), Camps e Milian (2000), Tolchinsky (2000) e Gombert (1996) a respeito da consciência que regula o agir por meio da linguagem ou consciência metalinguística. Esses autores utilizam a noção de contínuo entre ações de linguagem automáticas e irreflexivas, ações mais conscientes reguladas por generalizações implícitas ou epilinguísticas, e ações plenamente conscientes reguladas por conhecimentos e termos metalinguísticos. Para essa concepção da atividade metalinguística, o conhecimento disponível é um fator fundamental, pois a atividade metalinguística consciente é mediada por conhecimentos que permitem a operação reflexiva (CAMPS; MILIAN, 2000). Esse conhecimento deriva da interação com outros, que propiciam a incorporação de meios para a regulação do agir linguageiro do agente. Dessa concepção decorre que a atividade metalinguística é uma prática em permanente co-construção e de caráter fortemente contextual (PITTARD; MARTLEW, 2000), uma vez 
que permite a manutenção da correspondência entre as ações desenvolvidas e as representações sobre o contexto (CAMPS; MILIAN 2000; CASTELLÓ, 2000; PITTARD; MARTLEW, 2000).

A concepção da atividade metalinguística adotada supõe que o ensino de conhecimentos sobre a linguagem pode incidir na forma como os estudantes levam a cabo a regulação de sua produção de texto. Nossa visão da aprendizagem desses conhecimentos se situa no marco dos trabalhos do ISD. Este movimento trabalha sob a premissa vygotskyana (2009) de que o desenvolvimento humano depende da interação e da decorrente apropriação da cultura do grupo social a que se pertence (DOLZ; GAGNON; DECÂNDIO, 2019). No caso específico da linguagem, entende-se que os gêneros de texto são ferramentas portadoras dos conhecimentos necessários para agir em sociedade (DOLZ; GAGNON; DECÂNDIO, 2019) e que, por isso, eles fazem parte da aprendizagem linguística tanto dentro quanto fora da escola (DOLZ; SCHNEUWLY, 2004). Assim, o ISD propõe didatizar os gêneros por meio de SDs organizadoras das intervenções para ensinar a realizar certas ações de linguagem por meio de um gênero (DOLZ; SCHNEUWLY, 2004; CRISTOVÃO; STUTZ, 2011). Nessas sequências, são mobilizados conhecimentos praxiológicos, da arquitetura textual e dos mecanismos de textualização e enunciativos. Esses conhecimentos são abordados em módulos ou oficinas (DOLZ; NOVERRAZ; SCHNEUWLY, 2004), a partir da análise de textos autênticos e da realização de atividades de produção e de refaç̧ão de texto (CRISTOVÃO, 2009).

Os módulos das SDs são âmbitos de interação principalmente metalinguística em que os alunos e o professor constroem conhecimentos sobre o gênero por meio de um vocabulário comum (DOLZ; NOVERRAZ; SCHNEUWLY, 2004). Nessas interações, é propiciado o distanciamento da prática de produzir texto, a objetivação do funcionamento da linguagem e a reflexão sobre o próprio agir, processos necessários ao desenvolvimento da autorregulação (DOLZ; ERARD, 2000). A respeito dessas instâncias de interação metalinguística, o trabalho de Pontara e Cristovão (2017) incorporou à engenharia didática do ISD as propostas de Geraldi $(1991 ; 1996)$ para o ensino por meio da análise linguística 5 .

Geraldi (1991) propõe que as atividades de escrita e de leitura sejam complementadas com atividades que tomem a própria linguagem como tema de

\footnotetext{
${ }^{5} \mathrm{O}$ trabalho das autoras também toma como base as propostas metodológicas de Travaglia (2006; 2007).
} 
discussão, partindo da concepção binária de atividade metalinguística apresentada por Culioli e Normand (2005). Assim, o autor propõe a realização de atividades que incidam no nível epilinguístico, menos consciente e mais apegado às situações concretas de uso, e atividades que apontem ao nível metalinguístico, mais consciente, generalizado e auxiliado pela metalinguagem. Dessa forma, as atividades epilinguísticas promovem reflexões em torno de aspectos de uma produção textual concreta, enquanto as metalinguísticas promovem o estabelecimento de generalizações sobre os recursos da linguagem analisados nas atividades epilinguísticas, utilizando uma metalinguagem adequada.

\section{Metodologia}

O objetivo da pesquisa apresentada neste artigo é ter evidências da atividade metalinguística (grupal e individual) de uma turma de estudantes, que nos permitam analisar o impacto das atividades epilinguísticas e metalinguísticas utilizadas. Trabalhamos com base em dados obtidos em um curso quadrimestral de português como L2, ofertado em uma universidade pública brasileira, para a preparação do Exame CelpeBras. Esse exame afere a proficiência na língua escrita por meio de quatro tarefas de produção de texto a partir de diferentes gêneros. Um dos gêneros solicitados nessas tarefas é o artigo de opinião (SCHOFFEN et al. 2018), que foi ensinado na SD cujos resultados analisamos.

Essa SD foi composta de 13 oficinas de 2 horas, conduzidas pelo primeiro autor deste artigo, que também realizou as entrevistas descritas mais adiante. No tempo restante, esse autor participou assistindo ao outro professor, responsável pelo curso. Foram abordados diversos conhecimentos praxiológicos e linguístico-discursivos relacionados com o gênero e com as situações sociais que o suscitam mais comumente. Dentre eles: a) o lugar social do gênero artigo de opinião no debate social e político no país; b) o cenário de opiniões possíveis em torno do tema que um artigo de opinião pode apresentar; c) as possíveis estratégias de organização do artigo; e d) o uso de expressões de opinião, conectores lógicos, expressões de modalização e termos de valor apreciativo ou depreciativo.

Como consideramos que a atividade metalinguística ocorre na interação constante entre os marcos intersubjetivo e intrasubjetivo, conectados por meio da linguagem, foram 
utilizadas técnicas de produção de dados que trouxessem evidências de ambas as faces dessa atividade. Para obter evidências da atividade metalinguística grupal na aula, foram gravadas e transcritas todas as interações suscitadas por atividades epilinguísticas e metalinguísticas, a fim de ter evidências da evolução da atividade metalinguística dessa natureza ao longo de toda a SD. Para obter evidências da atividade metalinguística interna que acompanha a produção dos textos, foram realizadas entrevistas retrospectivas a duas produções escritas do gênero artigo de opinião, uma de caráter diagnóstico, no início da SD, e outra, de avaliação, no final da SD. Essas produções foram feitas a partir de uma situação social derivada de uma tarefa anterior do Exame CelpeBras. A situação consistia em assumir o papel de um representante do Tribunal Superior Eleitoral do Brasil para defender, por meio de um artigo de opinião, a segurança da urna eletrônica nos meses prévios à realização das eleições ${ }^{6}$.

As entrevistas foram realizadas imediatamente depois de que os alunos entregaram seus textos. Nelas, pedimos que evocassem seus pensamentos durante 0 processo de escrever, a partir de perguntas abertas previamente elaboradas (DÍAZ; QUEVEDO-CAMARGO, 2020). O objetivo de realizar as entrevistas nesses dois momentoschave da SD foi obter possíveis evidências de transformações na atividade metalinguística, levando em consideração o possível impacto dos processos de ensino levados a cabo na SD.

A turma de alunos participantes ${ }^{7}$ estava composta por seis estudantes adultos cujas características gerais se descrevem na Tabela 1. Tratava-se de uma turma majoritariamente integrada por alunos com muitos anos de escolarização formal. Suas idades eram muito variadas, seus gêneros equilibrados e eram diversos os motivos de residência no Brasil, assim como as primeiras línguas. No entanto, todos tinham em comum ter residido no Brasil por pelo menos 2 anos, possuir atividades externas ao curso em contexto de circulação social da língua, e ter participado dos cursos de PL2 de níveis Básico e Intermediário ofertados pela instituição sede do curso em que se aplicou a SD.

\footnotetext{
6 A tarefa, correspondente à segunda edição de 2018 do Exame Celpe-Bras, pode ser consultada no site http://www.ufrgs.br/acervocelpebras/acervo. Acesso em: out. 2021.

7 Por ter implicado a participação pessoas, a pesquisa foi submetida ao Comitê de Ética em Pesquisa da nossa universidade, aderido à Plataforma Brasil, tendo seu protocolo aprovado (CAAE 10092919.5.0000.5540).
} 
Tabela 1 - Características dos estudantes do curso de preparação para o Exame Celpe-Bras.

\begin{tabular}{|r|c|c|l|c|c|c|c|}
\hline ALUNo & IDADE & GÊNERo & $\begin{array}{c}\text { Nível MAIS ALTO } \\
\text { DE ESTUDOS }\end{array}$ & $\begin{array}{c}\text { ANOS DE } \\
\text { RESIDÊNCIA NO } \\
\text { BRASIL }\end{array}$ & $\begin{array}{c}\text { ANOS DE CONTATO } \\
\text { COM O } \\
\text { PORTUGUÊs }\end{array}$ & L1 & $\begin{array}{c}\text { ATIVIDADE } \\
\text { PRINCIPAL }\end{array}$ \\
\hline 1 & $40-50$ & $\mathrm{M}$ & Ensino médio & 15 & 15 & Turco & Trabalho \\
\hline 2 & $30-40$ & $\mathrm{M}$ & Pós-Graduação & 3 & 3 & Espanhol & Trabalho \\
\hline 3 & $30-40$ & $\mathrm{~F}$ & Pós-Graduação & 2 & 2 & Espanhol & Estudo \\
\hline 4 & $20-30$ & $\mathrm{M}$ & Pós-Graduação & 2 & 10 & Japonês & Trabalho \\
\hline 5 & $20-30$ & $\mathrm{~F}$ & Graduação & 5 & 5 & Coreano & Estudo \\
\hline 6 & $20-30$ & $\mathrm{~F}$ & Graduação & 2 & 2 & Espanhol & Estudo \\
\hline
\end{tabular}

Fonte: elaboração dos autores, 2021.

Embora tenha sido feita uma prova de diagnóstico da escrita do gênero artigo de opinião no início da SD, o nível de proficiência global dos alunos não foi medido com nenhum instrumento específico. Porém, como o Celpe-Bras só certifica os níveis a partir de Intermediário, todos os alunos consideravam estar próximos desse nível, uma vez que o curso tinha a finalidade específica de prepará-los para a dinâmica da prova e não a de fazê-los avançar sensivelmente em seu nível de proficiência. De uma maneira geral, tratava-se de estudantes capazes de utilizar a língua portuguesa em interações na sala de aula e na produção de vários textos escritos.

Os dados que derivam das interações realizadas em sala de aula têm como participantes todos os estudantes. Já os dados que derivam das entrevistas são de apenas duas alunas. A escolha de um número menor de participantes para as entrevistas se justifica pelo volume expressivo de dados que o tipo de técnica utilizada proporciona e pelo tipo de análise levada a cabo, isto é, uma análise microgenética aprofundada de cada processo individual de desenvolvimento (VYGOTSKY, 2009). Essas duas alunas foram selecionadas seguindo dois critérios. $O$ primeiro deles foi que tivessem participado integralmente da realização da SD. Além disso, buscou-se ter alunos de diferentes faixas etárias, já que essa era uma das características da turma. Portanto, apresentamos as análises a partir do que consideramos duas participantes paradigmáticas do processo levado a cabo, uma com idade entre 20 e 30 anos e outra com idade entre 30 e 40 .

A análise das interações em sala de aula e das entrevistas foi qualitativa (CHIZZOTTI, 2006; RICHARDSON, 1994) e buscou categorizar os depoimentos dos participantes em função dos conteúdos da atividade metalinguística (aspectos culturais e ideológicos do gênero, características da situação de produção do texto, organização do conteúdo temático, seleção de unidades linguístico-discursivas). A categorização também levou em conta a metalinguagem utilizada para referi-la. 
Para este artigo, foram selecionadas apenas atividades didáticas relacionadas com a modalização, um dos conhecimentos ensinados na SD. Por isso, também são apresentados apenas os excertos das entrevistas que remetem a esse aspecto da regulação da produção dos textos realizados pelos alunos participantes.

\section{Análise das evidências de atividade metalinguística grupal e individual}

Os modelos de atividades epilinguísticas e metalinguísticas propostos por Geraldi (1991; 1996) foram utilizados para o planejamento de atividades para o ensino de conhecimentos sobre o artigo de opinião, que foram incorporadas aos módulos da SD, junto com atividades de compreensão de textos-modelo e atividades de produção escrita. Tal como proposto pelo autor, as atividades epilinguísticas e metalinguísticas foram encadeadas: primeiro eram observados aspectos da construção de sentido dos textos, em atividades exploratórias, e depois eram realizadas atividades de generalização dos conhecimentos descobertos.

A atividade epilinguística apresentada a seguir (Quadro 1) foi planejada para abordar a função pragmática da oração modalizadora deôntica8 "é indispensável" (BRONCKART, 1999; CASTILHO, 2016; KOCH; 2015), presente no artigo de Paula Cesarino (2019) "A bem da verdade histórica", do jornal Folha de São Paulo.

Quadro 1 - Atividade epilinguística sobre modalização.

"Em outras palavras, a recuperação do passado pelo jornalismo é indispensável, além do óbvio e obrigatório relato detalhado e fiel do presente, o que não significa que o passado deve reger o presente, porque este fará do passado o uso que preferir."

1. Observe o parágrafo anterior novamente e reconheça:

a) Qual é o tempo verbal predominante nele?

b) Os fatos são apresentados como certos ou duvidosos?

c) Há alguma expressão que reforce essa percepção?

Fonte: elaborado pelos autores.

\footnotetext{
8 De acordo com Bronckart (1999) a modalização permite adequar o texto às condições pragmáticas por meio da inserção de avaliações dos objetos de discurso apresentados pelas diferentes vozes do texto. É possível identificar quatro funções da modalização: a modalização lógica, que expressa avaliações relacionadas com as coordenadas do mundo objetivo e com as condições de verdade dos conteúdos do texto; a modalização deôntica, relativa à adequação dos objetos de discurso ao "dever ser" das regras constitutivas do mundo social; a modalização pragmática, que apresenta aspectos de responsabilidade das entidades que são agentes das ações que fazem parte do conteúdo do texto, atribuindo-Ihes intenções, razões, ou ainda capacidades; e a modalização apreciativa, que explicita uma avaliação subjetiva de satisfação ou insatisfação a respeito de algum aspecto do conteúdo temático.
} 
Propostas de ensino de conhecimentos linguístico-discursivos em português (segunda língua) e desenvolvimento da atividade metalinguística

A atividade propõe que os alunos realizem uma prática de análise linguística centrada em compreender o efeito de sentido que a expressão produz no texto. Essa prática encontra-se mediada tanto pelo contexto significativo do texto, quanto pelo desenho da atividade, que direciona a reflexão do aluno. Esse tipo de atividade propõe um distanciamento da interação com o texto e a objetivação dos mecanismos da linguagem que operam em sua constituição significativa.

O Quadro 2 apresenta a transcrição da discussão grupal ${ }^{9}$ em que os alunos socializaram suas respostas à última pergunta da atividade sobre modalização. $\mathrm{Na}$ interação, que constitui uma elaboração metalinguística grupal, vê-se a importância da intervenção docente para conduzir a análise linguística e a dificuldade dos alunos para tomar a língua como objeto de análise, que se espelha na simplicidade das respostas e na necessidade de explicações ou perguntas do professor.

Quadro 2 - Interação metalinguística a partir de uma atividade epilinguística.

\begin{abstract}
Professor - Mas, não é o único recurso que tem um artigo para afirmar. Tem outro recurso além do presente para dar a ideia de certeza, vocês perceberam qual é?
\end{abstract}

Aluna 3 - Sim

Professor - Que expressão ajuda a reforçar?

Aluna 3 - Acho que onde ele diz "obrigatório relato detalhado fiel do presente"

Professor -"Obrigatório", a palavra obrigatório... ótimo! "Obrigatório", ela diz que "além do óbvio e obrigatório relato do presente", algo que é obrigatório e algo que é? Obrigatório basicamente né?

Aluna 3 - Que tem que ser.

Professor - Tá adorei. E tem outra expressão parecida a "é obrigatório" que reforça também nesse mesmo parágrafo...

Aluno 1 - Eu acho que esta!

Aluno 2 - Eu havia respondido "Além do óbvio". Professor - "Além do obvio", você gostou da palavra "óbvio", se parece com obrigatório também né?

Aluna 3 - "É indispensável".

Professor - Que significa que uma coisa é óbvia?

Aluno 2 - É.

Aluno 2 - Porque a maioria das pessoas conhece.
Professor - Isso! É uma verdade óbvia. Então, quando ela seleciona as palavras "óbvio" e as palavras "obrigatório" está reforçando a ideia de verdade né? Se ela falasse em lugar de... Que seria o oposto de "óbvio"? "Obvio" é súper certo...

Aluna 6 - Dúvida.

Professor - Dúvida. Poderia ser duvidoso, "é possível". Mas o que é óbvio não tem dúvida, não há discussão. $E$ algo que é obrigatório é a mesma coisa, adorei Aluno 2, perfeito!

Aluna 3 - Duvidoso.

Aluna 3 - Possível.

Aluno 1 - Tem, aqui, no "recuperação" também?

Professor - Qual, Aluno 4, qual?

Aluna 6 - "Do passado"

Professor - "Recuperação..." "Recuperação", sim, sim. "A recuperação do passado..."

Aluna 3 - "É indispensável..."

Professor - A palavra recuperação do passado vem sendo uma palavra da temática né? Mas vamos ver a oração, diz "a recuperação do passado pelo jornalismo é indispensável além do obvio e obrigatório relato detalhado do presente".

Aluna 3 - "Indispensável" é a outra palavra.

Fonte: elaboração dos autores

\footnotetext{
${ }^{9}$ Inadequações de caráter gramatical que não alteravam os conteúdos dos enunciados foram editadas na transcrição das interações orais apresentadas neste artigo, a fim de tornar sua leitura mais acessível.
} 
A interação grupal mostra um processo de análise linguística que se constrói conjuntamente a partir das intervenções do professor e dos estudantes, que conformam uma atividade metalinguística conjunta (DOLZ; ERARD, 2000). Isso se evidencia no encadeamento entre os raciocínios metaverbais produzidos pelo professor e pelos alunos. É evidente que as intervenções do professor guiam a análise e que os alunos reelaboram sua atividade metalinguística a partir dessa guia, mas também é claro que a própria atividade epilinguística proposta direciona os alunos a compreender, a partir de sucessivas aproximações, o sentido pragmático das expressões. Eis o caso da análise sucessiva das expressões "óbvio", "é obrigatório" e "é indispensável", cada uma sustentada pela anterior. É importante também observar a presença de termos metalinguísticos que medeiam a análise, tais como "expressões", "reforçar/reforço", "certeza", "dúvida/duvidoso", "possível".

A atividade epilinguística anterior foi sucedida pela realização de uma atividade metalinguística que tinha a finalidade de que os alunos sintetizassem e verbalizassem suas descobertas por meio da formulação de uma regra prática (Quadro 3).

Quadro 3 - Atividade metalinguística sobre modalização.

Seguindo o formato dado, escreva uma regra de uso que sintetize o que você acabou de observar sobre o uso de expressões de ênfase ou modalização

FORMULANDO UMA REGRA PRÁTICA

Ao escrever um artigo podemos...

Isso nos serve para...

Tomando cuidado de não...

Fonte: elaborado pelos autores.

A atividade propõe uma análise linguística mais distanciada, com caráter generalizado e, por isso, requer uma articulação metalinguística mais complexa. A interação grupal de construção da regra em comum (Quadro 4) mostra que ambas as características tornam a atividade mais desafiadora para os estudantes, que realizam intervenções breves. Porém, a interação parece propiciar um aprofundamento da compreensão do conhecimento em questão, assim como a realização de análises linguísticas mais complexas, como as evidenciadas nas formulações "Para expressar que os argumentos são fatos", "Para reforçar os argumentos" e "De não usar expressões que indiquem outra coisa ou o contrário". Nessa interação, são utilizados os mesmos termos 
Propostas de ensino de conhecimentos linguístico-discursivos em português (segunda língua) e desenvolvimento da atividade metalinguística

metalinguísticos que auxiliaram a análise na atividade anterior: "expressões", "dúvida", "reforçar".

Quadro 4 - Interação metalinguística a partir de uma atividade metalinguística.

\begin{tabular}{|c|c|}
\hline $\begin{array}{l}\text { ffessor - "Formulando uma regra prática. Ao } \\
\text { rever um artigo podemos..." Qual vai ser a } \\
\text { ra que a gente vai inferir disso que acabemos } \\
\text { ver? "Ao escrever um artigo podemos..." Que } \\
\text { lemos fazer? } \\
\text { Ina } 3 \text { - Expressões. } \\
\text { fessor - Podemos? } \\
\text { ina } 3 \text { - Ter expressões. } \\
\text { fessor - "Ter expressões, expressões } \\
\text { no...". Podemos colocar um exemplo. } \\
\text { Ina } 3 \text { - Como "é indispensável", "é obrigatório". } \\
\text { fessor - Ou "é obrigatório', bem. "Isto nos } \\
\text { ve para...". Para que nos servem essas } \\
\text { ressões? } \\
\text { Ina } 3 \text { - Para... } \\
\text { Ino } \mathbf{1} \text { - Para dúvida né? } \\
\text { fessor - Para as dúvidas, sim. Eu sei o que } \\
\text { ê está pensando e está certo, mas se você me } \\
\text { ir assim... Como assim "para as dúvidas"? } \\
\text { lica. } \\
\text { Ino } 2 \text { - Para expressar que os argumentos são } \\
\text { ss. } \\
\text { Ina } 3 \text { - Para reforçar os argumentos. }\end{array}$ & $\begin{array}{l}\text { Professor - Para reforçar os argumentos e } \\
\text { eliminar as dúvidas. "Tomando cuidado de não...". } \\
\text { Qual poderia ser o cuidado que temos de tomar? } \\
\text { Aluna } 3 \text { - De não usar expressões que indiquem } \\
\text { outra coisa ou o contrário. } \\
\text { Professor - Por exemplo? Qual seria o contrário } \\
\text { de certeza? Qual é o contrário de certeza? } \\
\text { Aluno } 1 \text { - Dúvida } \\
\text { Professor - Dúvida. Eu posso me enganar e } \\
\text { utilizar uma expressão como "é possível". } \\
\text { Aluna } 3 \text { - "É provável" } \\
\text { Professor - Aí estou me enganando, porque aí } \\
\text { estou dando a ideia de dúvida e não de certeza. } \\
\text { Então, "Tomando cuidado de não usar } \\
\text { expressões..." } \\
\text { Aluna } 3 \text { - Que indiquem dúvida... } \\
\text { Professor - "Que indiquem dúvida como..." } \\
\text { Aluna } 3 \text { - "Provável" } \\
\text { Professor - Que indiquem dúvida, como "é } \\
\text { provável" ou "é possível". Ótimo! Então, vamos } \\
\text { pensar... Não quer dizer que a gente não vai usar } \\
\text { essas expressões, a gente usa essas expressões, } \\
\text { mas não para nossos argumentos. }\end{array}$ \\
\hline
\end{tabular}

Fonte: elaboração dos autores

Essas breves amostras de interações metalinguísticas exemplificam que as atividades epilinguísticas e metalinguísticas ${ }^{10}$ propiciaram um processo de construção grupal de conhecimento baseado na prática da análise linguística e mediado pelas atividades didáticas, pela condução do professor, e por um conjunto de termos metalinguísticos, constituindo uma zona de desenvolvimento proximal (VYGOTSKY; 2009) quanto à reflexão sobre a linguagem em diferentes níveis de generalização.

Nos parágrafos anteriores, analisamos a realização de atividades epilinguísticas e metalinguísticas na sala de aula. Nos seguintes parágrafos, abordaremos indícios da atividade metalinguística individual levada a cabo ao escrever um texto do gênero artigo de opinião com base em excertos de entrevistas retrospectivas a duas instâncias de produção escrita, no início e no final da SD. Utilizaremos evidências das entrevistas de

\footnotetext{
${ }^{10}$ É importante salientar que, ao longo de toda a SD, foram realizadas sucessivas atividades dessa natureza, abordando
} a modalização, assim como outros conhecimentos linguístico-discursivos relacionados com o gênero artigo de opinião. 
duas estudantes, a Aluna 3 e a Aluna 6 (Tabela 1). Nessa análise, assumimos que as lembranças que foram comentadas nas entrevistas correspondem à mobilização de representações conscientes instrumentais à regulação da escrita (CAMPS; MILIAN, 2000; CASTELLÓ, 2000). A comparação entre os dois momentos da SD busca reconhecer mudanças qualitativas, que podem ter sido motivadas pelo trabalho didático realizado. Para os propósitos deste artigo, manteremos o foco na modalização.

A análise das entrevistas no momento em que as alunas foram induzidas a comentar a seleção de unidades linguístico-discursivas ou estratégias de textualização (Quadro 5) mostra algumas diferenças quanto aos conhecimentos mobilizados e também quanto à metalinguagem. Nas primeiras, ambas referem-se à seleção da informação como principal operação argumentativa. Nesse caso, podemos inferir que parte da atividade metalinguística interna está guiada por conhecimentos relativos ao potencial argumentativo das informações. Entretanto, nas entrevistas posteriores à SD, há evidências de atenção dedicada à seleção das unidades linguístico-discursivas e seu potencial para dar sustentação à argumentação.

Quadro 5 - Evidências da atividade metalinguística interna Entrevista anterior à SD, Aluna 3

Professor - Como você transmitiu? Você lembra de que forma você transmitiu essa segurança? Se teve alguma estratégia que você usou?

Aluna 3 - Bom, eu falei muito do aparelho, da urna eletrônica. Que é um sistema eletrônico, que tinha um software, que com o software que ele fazia um programa...

Professor - Parecem coisas mais confiáveis as tecnológicas...

Aluna 3 - Sim. Tecnológicas. E que tinham que mudar os hábitos deles, de ficar com o sistema antigo. E que eles tinham que mudar para um sistema tecnológico porque já no ano 1996 se fala que é uma época eletrônica, então, não podem ficar sem atualização.

Entrevista posterior a la SD, Estudiante 2

Professor - Você lembrou de algumas expressões que você queria usar?

Aluna 3 - Sim! Porque de todas essas regras, todas tem relações, mas é difícil de aprender todas de uma vez, então eu me foquei as que são afirmar e as que são para negar. Então, quando, neste caso, que é a favor e não podia usar em contra, porque senão isso ia ficar se contradizendo.

Professor - E aí você focou nas expressões para afirmar?

Aluna 3 - Sim, para afirmar, mas também eu usei de dúvida, para focar a parte da sociedade, mas depois eu usei dando certeza de que tem que acreditar no sistema.

Entrevista anterior à SD, Aluna 6

Professor - Você falou varias vezes que você tem certeza. Como você expressou essa ideia? Você lembra que expressões usou? Como você transmitiu essa certeza?

Aluna $\mathbf{6}$ - Como eu transmiti? Eu transmiti, como você me falou, criando argumentos. Eu não posso colocar "eu tenho certeza" se eu não estou dando nenhum tipo de argumento. Porque eles vão falar "eu tenho", "ele fala 'eu tenho', 'eu tenho'". Mas, ao cidadão não importa a palavra dele, ele precisa argumentos. E você sabe como é o cidadão, como esse relacionamento com pessoas é uma coisa difícil. 
Para mim, o trabalho mais difícil é quando você tem essa relação com as pessoas e você tem que oferecer esse tipo de segurança. Então, primeiro eu coloquei um argumento, porque primeiro eu não posso colocar que eu tenho a certeza. Não, primeiro coloquei um argumento e já depois eu coloquei que eu oferecia essa segurança para o cidadão.

Entrevista posterior à SD, Aluna 6

Professor - Quando você apresentou umas pessoas e outras, você se preocupou com alguma coisa sobre como expressar essas ideias?

Aluna 6 - Sim, eu me preocupei em colocar a outra voz, mas que não fique como a minha voz, porque eu posso colocar "embora muita gente tenha dúvidas, o TSE não!!!". Nós não temos. Então, eu pensei muito, porque é difícil colocar outra ideia contrária, contraditória e que depois fique como a minha. Não é o que eu quero, porque eu não estaria fazendo uma coisa... Então eu tentei colocar "embora" e depois quando eu acrescentei a palavra TSE, que é a organização que oferece essa segurança, tentei que ficasse bem claro que nós estamos tentando defender.

Professor - Como você conseguiu que isso ficasse bem claro?

Aluna 6 - Eu coloquei "embora muita gente tenha dúvidas, o TSE tem a certeza de que a urna eletrônica...". Não que o TSE tem certeza de que isso é certo ou não, o TSE tem certeza de que a urna eletrônica é uma ferramenta fundamental para o povo brasileiro e é uma ferramenta sem corrupção, justa e limpa.

Fonte: elaboração dos autores

A atenção específica à metalinguagem utilizada nas segundas entrevistas mostra o uso das expressões metalinguísticas que circulavam na sala de aula durante a realização de atividades epilinguísticas e metalinguísticas sobre modalização. A Aluna 3 utiliza os termos "afirmar", "negar", "a favor", "em contra", "dúvida" e "certeza"; por sua vez, a Aluna 6 utiliza os termos, "outra voz", "ideia contrária", "defender", "certeza".

Essas análises justificam propor que as atividades didáticas epilinguísticas e metalinguísticas propiciaram a interiorização de conhecimentos e de metalinguagem sobre a modalização, que teriam intervindo, pelo menos em parte, como mediadores da atividade metalinguística individual das alunas, isto é, que a zona de desenvolvimento proximal provocada nas interações grupais teria sido deslocada também ao processo de regulação da produção escrita.

\section{Conclusão}

As análises parciais apresentadas neste artigo mostram que as atividades epilinguísticas e metalinguísticas inseridas em uma SD são procedimentos metodológicos eficazes para o ensino dos conhecimentos linguístico-discursivos no ensino de um gênero em português como L2. Essas atividades tornam mais acessíveis as aproximações aos saberes devido ao seu caráter co-construído com o outro. Essa co-construção parece repercutir positivamente no processo de autorregulação individual da escrita, mediado 
pela metalinguagem aprendida. Por sua vez, há indícios de que sua orientação aos níveis epilinguístico e metalinguístico de forma diferenciada favorece o desenvolvimento progressivo da apropriação dos conhecimentos linguístico-discursivos como meios de regulação da escrita. Pesquisas posteriores devem ser desenvolvidas a fim de ampliar as evidências empíricas do impacto desse tipo de atividade nas aprendizagens.

\section{Referências}

BAKHTIN, Mikhail. El problema de los géneros discursivos. In: BAKHTIN, Mikhail. Estética de la creación verbal. Buenos Aires: Siglo Veintiuno, 2008. p. 245-290.

BRANDÃO, Luana. Uma análise sociodiscursiva do sufixo-inho em materiais didáticos. uma contribuição para a constituição de sentidos no ensino de português para estrangeiros. 2010. Tese (Mestrado em Linguística) - Instituto de Letras, Universidade de Brasília, Brasília, 2010.

BROCCO, Aline. A gramática em contexto teletandem e em livros didáticos de português como língua estrangeira. 2009. Dissertação (Mestrado em Estudos Linguísticos) Faculdade de Letras, Universidade Estadual Paulista, São Paulo, 2009.

BRONCKART, Jean-Paul. Atividade de linguagem, textos e discursos. Por um interacionismo sociodiscursivo. São Paulo: EDUC, 1999.

BRONCKART, Jean-Paul; DOLZ, Joaquim. La notion de compétence: quelle pertinence pour I'étude de I'apprentissage des actions langagières? Raisons Éducatives, [s. I.], $\mathrm{n}$. 2, p. 27-44, 1999.

BRONCKART, Jean-Paul. Ação, discurso e racionalização: a hipótese de desenvolvimento de Vygotsky revisitada. In: MATENCIO, Maria de Lourdes; MACHADO, Ana Raquel (org.). Atividade de linguagem, discurso e desenvolvimento humano. São Paulo: Mercado de Letras, 2009. p. 59-91.

CAMPS, Anna. Actividad metalingüística y aprendizaje de la gramática: hacia un modelo de enseñanza basado en la actividad reflexiva. Cultura y Educación, Madrid, v. 21, n. 2, p. 199-203, 2009.

CAMPS, Anna; MILIAN, Marta. La actividad metalingüística en el aprendizaje de la escritura. In: CAMPS, Anna; MILIAN, Marta (org.). El papel de la actividad metalinguística en el aprendizaje de la escritura. Rosario: Homo Sapiens, 2000. p. 7-37.

CAMPS, Anna et al. Actividad metalingüística: la relación entre escritura y aprendizaje de la escritura. In: CAMPS, Anna; MILIAN, Marta (org.). El papel de la actividad metalinguística en el aprendizaje de la escritura. Rosario: Homo Sapiens, 2000. p. 135162.

CASTELLÓ, Monserrat. Las concepciones de los estudiantes sobre la escritura académica. In: CAMPS, Anna; MILIAN, Marta (org.). El papel de la actividad metalinguística en el aprendizaje de la escritura. Rosario: Homo Sapiens, 2000. p. 67- 
Propostas de ensino de conhecimentos linguístico-discursivos em português (segunda língua) e desenvolvimento da atividade metalinguística

104.

CASTILHO, Ataliba de. Nova gramática do português brasileiro. São Paulo, Cortez, 2016.

CELCE-MURCIA, Marianne. Grammar Pedagogy in Second and Foreign Language Teaching. Tesol Quarterly, Washington, v. 25, n. 3, p. 459-480, 1991.

CESARINO, Paula. A bem da verdade histórica. Tentativas de reescrever a história exigem que se ilumine passado e presente. Folha de São Paulo, São Paulo, 07 abr. 2019. Disponível em: https://www1.folha.uol.com.br/colunas/paula-cesarino-costaombudsman/2019/04/a-bem-da-verdade-historica.shtml. Acesso em: nov. 2019.

CHIZZOTTI, Antonio. Pesquisa qualitativa em ciências humanas e sociais. Rio de Janeiro: Vozes, 2006.

CRISTOVÃO, Vera Lúcia. Sequências didáticas para o ensino de línguas. In: DIAS, Reinildes; CRISTOVÃO, Vera Lúcia (org.). O livro didático de língua estrangeira: múltiplas perspectivas. Campinas: Mercado de Letras, p. 305-344, 2009.

CRISTOVÃO, Vera Lúcia; STUTZ, Lidia. Sequências didáticas: semelhanças e especificidades no contexto francófono como L1 e no contexto brasileiro como LE. In: SZUNDY, Paula Tatianne et al. (org.). Linguística aplicada e sociedade: ensino e aprendizagem de línguas no contexto brasileiro. Campinas: Pontes, 2011. p. 17-39.

CULIOLI, Antoine; NORMAND, Claudine. Onze rencontres sur le langage et les langues. Paris: Ophrys, 2005.

DÍAZ, Damián. A reflexão metalinguística sobre a modalização no artgo de opinião em uma sequência didática de prepaparação para o Exame Celpe-Bras. 2019. Dissertação (Mestrado em Linguística Aplicada) - Instituto de Letras, Universidade de Brasília, Brasília, 2019.

DÍAZ, Damián; QUEVEDO-CAMARGO, Gladys. Atividade metalinguística e técnicas de produção de dados para a análise da aprendizagem de português como segunda língua. ReVEL - Revista Virtual de Estudos da Linguagem, [s. l.], v. 18, n. 35, p. 147-180, 2020.

DOLZ, Joaquim; ERARD, Serge. Las atividades metaverbales en la enseñanza de los géneros escritos y orales. In: CAMPS, Anna; MILIAN, Marta. (org.). El papel de la actividad metalingüística en el aprendizaje de la escritura. Rosario: Homo Sapiens, 2000. p. 163-186.

DOLZ, Joaquim; SCHNEUWLY, Bernard. Em busca do culpado. Metalinguagem dos alunos na redação de uma narrativa de enigma. In: DOLZ, Joaquim; SCHHNEUWLY, Bernard. Gêneros orais e escritos na escola. São Paulo: Mercado de Letras, 2004. p. 159-181.

DOLZ, Joaquim; NOVERRAZ, Michèle; SCHNEUWLY, Bernard. Sequências didáticas para o oral e a escrita: apresentação de um procedimento. In: DOLZ, Joaquim; SCHNEUWLY, Bernard. Gêneros orais e escritos na escola. São Paulo: Mercado de Letras, 2004. p. 81- 
108.

DOLZ, Joaquim; GAGNON, Roxane; DECÂNDIO, Fabrício. Uma disciplina emergente: a didática das línguas. In: NASCIMENTO, Elvira (org.). Gêneros textuais. da didática das línguas aos objetos de ensino. Campinas: Pontes, 2019. p. 21-50.

DONATO, Richard. Collective scaffolding in second language learning. In: LANTOLF, James; APPEL, Gabriela (org.). Vygotskian approaches to second language research. New Jersey: Ablex Publishing Corporation, 1994. p. 33-55.

FERRAZ, Andrea; PINHEIRO, Isabel. O desafio pós Clpe-Bras: relações entre o exame e o programa de estudantes-convênio de graduação. In: DELL'ISOLA, Regina (org.). 0 Exame de proficiência Celpe-Bras em foco. Campinas: Pontes, 2014. p. 131-141.

GERALDI, João Wanderley. Linguagem e ensino: exercícios de militância e divulgação. São Paulo: Mercado de Letras, 1996.

GERALDI, João Wanderley. Portos de passagem. São Paulo: Martins Fontes, 1991.

GOMBERT, Jean-Émile. Activités métalinguistiques et acquisition d'une langue. Aile: Acquisition et Interaction en Langue Étrangère, Saint-Denis, v. 8, p. 1-11, 1996.

KLETT, Estela. Lenguas extranjeras, comunicación y gramática: historia de una relación controertida. RASAL Lingüística, [s. I.], v. 2, p. 139-153, 2004.

KOCH, Ingedore. Argumentação e linguagem. São Paulo, Cortez, 2015.

KRUG, Marcelo Jacó. O ensino / aprendizagem da metafonia do português como língua estrangeira por aprendizes alemães. Revista Contingentia, Porto Alegre, v. 4, n. 2, p. 85-99, 2009.

LARSEN-FREEMAN, Dianne. Teaching grammar. In: CELCE-MURCIA, Marianne; BRINTON, Donna; SNOW, Marguerite Anne (org.). Teaching english as a second or foreign language. Boston: National Geographic Learning, 2014. p. 256-270.

LIMA, Cláudia Filipa. Gramática a /à distância. 2012. Dissertação (Mestrado em Ensino do Português como Segunda Língua ou Estrangeira) - Faculdade de Letras, Universidade Nova, Lisboa, 2012.

MACHADO, Ana Rachel. A perspectiva interacionista sociodiscursiva de Bronckart. In: MEURER, José Luís; BONINI, Adair; MOTTA-ROTH, Désirée (org.). Gêneros: teorias, métodos e debates. São Paulo: Parábola, 2005. p. 235-259.

MARCOTULIO, Leandro; PINHEIRO, Igor; ASSIS, Dalila. A relação entre pesquisa e ensino: o quadro de possessivos do português. Cadernos de Letras da UFF, Niterói, n. 51 , p. 239-260, 2015.

MAURÍCIO, Ernesto. Ensino estratégico da gramática na aula de português língua não materna. 2015. Tese (Doutorado em Estudos Portugueses) - Faculdade de Letras, Universidade Nova, Lisboa, 2015. 
MEDEIROS, Vanise. Os passados no ensino de português para estrangeiros. Soletras, Rio de Janeiro, n. 2, p. 76-82, 2001.

MELO, Maressa Carneiro de. Ensino da prosódia nos atos diretivos de ordem e pedido para falantes estrangeiros aprendizes do Português Brasileiro: uma análise de materiais didáticos. 2017 Dissertação (Mestrado Profissional em Educação), Universidade Federal dos Vales do Jequitinhonha e Mucuri, Diamantina, 2017.

MITELSTADT, Daniela; SANTOS, Letícia. A gente e nós e o seu tratamento em um livro didático de português como língua adicional. Cadernos do IL, Porto Alegre, n. 44, p. 432-456, 2012.

NADAIS, Bárbara. O léxico em aulas de PLE: um contributo para o ensino de colocações. 2009. Dissertação (Mestrado em Português Língua Segunda / Língua Estrangeira) - Faculdade de Letras, Universidade do Porto, Porto, 2009.

NASCIMENTO, Elvira. Apresentação. In: NASCIMENTO, Elvira (org.). Gêneros textuais: Da didática das línguas aos objetos de ensino. Campinas: Pontes, 2019. p. 7-17.

NORRIS, John; ORTEGA, Lourdes. Effectiveness of L2 instruction: a research synthesis and quantitative meta-analysis. Language Learning, Ann Arbor, v. 50, n. 3, p. 417-528, 2000.

PABST, Luiza. Lições de sintaxe do português brasileiro para estrangeiros. 2014. Dissertação (Mestrado em Teoria e Análise Linguística) - Faculdade de Letras, Universidade Federal do Rio Grande do Sul, Porto Alegre, 2014.

PITTARD, Vanessa; MARTLEW, Margaret. La cognición situada socialmente y la actividad metalinguística. In: CAMPS, Anna; MILIAN, Marta (org.). El papel de la actividad metalinguística en el aprendizaje de la escritura. Rosario: Homo Sapiens, 2000. p. $105-134$.

PONTARA, Cláudia Lopes; CRISTOVÃO, Vera Lúcia Lopes. Gramática/análise linguística no ensino de inglês (língua estrangeira) por meio de sequência didática: uma análise parcial. DELTA, São Paulo, v. 33, n. 3, p. 874-909, 2017.

PRATAS, Sara Alexandra. As formas de tratamento e o ensino de português como língua não materna. 2017. Dissertação (Mestrado em Português como Língua Estrangeira e Língua Segunda) - Faculdade de Letras, Universidade de Coimbra, Coimbra, 2017.

RICHARDSON, Laurel. Writing: a method of inquiry. In: DENZIN, Norman; LINCOLN, Yvonna (ed.). Handbook of qualitative research. London: Sage, 1994. p. 516-529.

RODRIGUES, Thaís. Os pronomes átonos e o ensino de português brasileiro a falantes de espanhol. In: SEMINÁRIO DOS ALUNOS DOS PROGRAMAS DE PÓS-GRADUAÇÃO DO INSTITUTO DE LETRAS DA UFF - ESTUDOS DE LINGUAGEM, 6., 2015, Niterói. Anais [...]. Niterói: UFF, 2015. p. 614-627.

SCHMIDT, Richard. The Role of consciousness in second language learning. Applied 
Linguistics, Oxford, v. 11, n. 2, p. 129-158, 1990.

SCHNEUWLY, Bernard. Gêneros e tipos de discurso: considerações psicológicas e ontogenéticas. In: DOLZ, Joaquim; SCHNEUWLY, Bernard. Gêneros orais e escritos na escola. São Paulo: Mercado de Letras, 2004. p. 19-34.

SCHOFFEN, Juliana et al. Estudo descritivo das tarefas das parte escrita do exame Celpe-Bras: edições de 1998 a 2017. Porto Alegre: Editora do Instituto de Letras UFRGS, 2018.

SILVA, Meire Celedônio. Gramática e letramento no ensino e na aprendizagem de português como língua adicional. BELT - Brazilian English Language Teaching Journal, Porto Alegre, v. 10, n. 1, p. 1-17, 2019.

SILVEIRA, Rosane; ROSSI, Albertina. Ensino da pronúncia de português como segunda língua: considerações sobre materiais didáticos. ReVEL - Revista Virtual de Estudos da Linguagem, [s. I.], v. 4, n. 7, p. 1-19, 2006.

TAFNER, Elisabeth. A expressão da futuridade nos manuais de ensino de português para estrangeiros. SOLETRAS, Rio de Janeiro, n. 9, p. 27-38, 2005.

TOLCHINSKY, Liliana. Distintas perspectivas acerca del objeto y propósito del trabajo y la reflexión metalingüística en la escritura académica. In: CAMPS, Anna; MILIAN, Marta (org.). El papel de la actividad metalinguística en el aprendizaje de la escritura. Rosario: Homo Sapiens, 2000. p. 39-65.

TRAVAGLIA, Luís Carlos. Gramática e interação: uma proposta para o ensino de gramática. São Paulo: Cortez, 2006.

TRAVAGLIA, Luís Carlos. Gramática: ensino plural. São Paulo: Cortez, 2007.

VYGOTSKY, Lev. Pensamento e linguagem. São Paulo: Martins Fontes, 1987.

VYGOTSKY, Lev. A formação social da mente: o desenvolvimento dos processos psicológicos superiores. São Paulo: Martins Fontes, 2009.

Submetido em: 01 out. 2021. Aceito em: 24 out. 2021. 